\title{
Libertad y propiedad: formas de apropiación de recursos comunes en el diseño institucional neoliberal chileno, 1973-2020
}

\author{
Freedom and property: forms of appropriation of common \\ resources in the Chilean neoliberal institutional design, \\ $1973-2020$
}

\section{Francisco Báez Urbina*}

\section{RESUMEN}

El presente artículo aborda el extenso fenómeno de la privatizaPalabras clave: ción de las instituciones que coordinan y regulan las relaciones bienes públicos, de producción y distribución entre agentes sociales y económicos. El texto, desde la historia y la teoría política, revisa algunos casos de apropiación de bienes colectivos observables en la últipropiedad, diseño institucional, neoliberalismo. ma modernización capitalista chilena (1973-2020), bienes considerados por la literatura de las ciencias sociales y económicas como ejemplos de apropiación de propiedad colectiva. De esta manera, intenta contribuir a corroborar, con casos nacionales, pero tomando como telón de fondo ejemplos de carácter más bien universal, el argumento esgrimido por la economía política republicana democrática, que sostiene que la neoliberalización actual es la última etapa del proceso capitalista de apropiación privada de la propiedad colectiva. Metodológicamente, este artículo se basó principalmente en la revisión documental de fuentes secundarias.

\section{SUMMARY}

This article addresses the privatization of institutions that reguKeywords: Public late production and distribution among social and economic agents. From the perspective of history and political theory, the goods, property, institutional 
text reviews some cases of the appropriation of collective goods observed in the last Chilean capitalist modernization (19732020), goods considered by the literature of social and economic sciences as examples of the appropriation of collective property. In this way, it confirms national cases, however also taking as a universal backdrop example, the argument put forward by the democratic-republican political economy that maintains that current neo-liberalization is the last stage of the capitalist process private appropriation of collective property. Methodologically, this article was based primarily on a documentary review of secondary sources. design, neoliberalism. 


\section{La apropiación de lo común, el capitalismo y la privatización de la sociedad}

La historia humana, en cierto sentido, es la historia de la propiedad, de la propiedad sobre uno mismo (ser propio o dueño de sí) o de las formas de la propiedad y la apropiación - legítima o no- de los recursos de la sociedad que aseguran la propia vida y la propia libertad. Desde este punto de vista, la historia no sería otra cosa que la historia de los mecanismos institucionales que distribuyen los bienes relevantes de y para la sociedad. Esto es, el reparto de oportunidades, roles o incluso espacios dentro de un determinado recurso común. Ahora bien, un recurso común puede ser entendido -y así lo haremos- como el resultado de un conjunto de contribuciones individuales y que puede o debe ser repartido de tal o cual manera. En este sentido, lo consideramos un bien público (BP). ${ }^{1}$ Un BP es un bien perfectamente no rival y no excluyente. No rivalidad u oferta conjunta significa que muchos individuos pueden disfrutar simultáneamente del bien, y que la suma de un nuevo consumidor no generará ningún coste adicional. No exclusión indicará que quien no paga por la provisión de dicho bien, no puede ser excluido de su goce. Tiene que ver con la posibilidad de evitar que las personas consuman un bien o servicio por el cual no han pagado, lo que depende de si los derechos de propiedad están claramente definidos o si pueden ser provistos a costes razonables. Una baja exclusión significa que es difícil evitar el free riding, esto es, impedir que alguien obtenga beneficios de dicho bien sin haber pagado por él. ${ }^{2}$

Aunque la perspectiva ranceriana no es la mirada desde la cual se construye esta reflexión, creemos que la definición del reparto que define el autor es bastante sugerente. El reparto de lo sensible sería ese "sistema de evidencias sensibles que al mismo tiempo hace visible la existencia de un común y los recortes que allí definen los lugares y las partes respectivas. Un reparto de lo sensible fija (...) un común repartido y partes exclusivas. Esta repartición de partes y de lugares se funda en un reparto de espacios, de tiempos y de formas de actividad que determina la manera misma en que un común se ofrece a la participación y donde los unos y los otros tienen parte en ese reparto" (2017: 9).

2 Ejemplos son la música de un saxo, el aire, la defensa nacional o la seguridad ciudadana. Un ejemplo contra intuitivo es el que plantea Ostrom: "Un mercado competitivo -el arquetipo de las instituciones privadas- es en sí mismo un BP. Una vez que se genera un mercado competitivo los individuos pueden entrar y salir libremente, ya sea que contribuyan o no con el costo de generarlo y mantenerlo" (2000: 43). Otro ejemplo es el concepto general intellect acuñado por Marx: el conocimiento general alcanzado por la sociedad también es un BP, y mientras algunos se apropian de los resultados de la investigación que es financiada con impuestos, son financiados por todos los contribuyentes. 
Según Aristóteles (Política, 1263A, 3-8), podemos distinguir entre tres formas de propiedad o apropiación: (1) el uso privado de propiedad común, (2) el uso común de propiedad privada, y (3) el uso común de propiedad común. La cuarta variante posible, el uso privado de propiedad privada, fue excluida voluntariamente por el autor, porque imposibilitaría la transferencia o la posibilidad de compartir lo propio en forma de donación o regalo (Domènech, 2010). Pues bien, quisiéramos argumentar a favor de la idea de que el capitalismo contemporáneo, tardío, avanzado, neoliberal o como quiera llamársele, aparte de haber destruido toda posibilidad de que la ciudadanía estime como conveniente o eficiente la modalidad (2) pues serviría de fundamento a la abolición de formas republicanas o comunitaristas de propiedad, y (3) pues serviría de fundamento a la abolición completa de la propiedad privada (comunismo utópico), en estos últimos 30 años ha venido ganando la batalla política y cultural para imponer la modalidad (1) como forma económica hegemónica, pese a que llevaría clara y expresamente a la Tragedia de los Comunes (TC). La TC retrata un patrón ubicuo y persistente que ilustra la compulsión individual a sobreutilizar o a sobreexplotar recursos escasos de propiedad comunal en función de la búsqueda del beneficio excluyente de cada agente (Hardin, 1968; Ostrom, 2000). ${ }^{3}$ Se sostendrá, entonces, que la libertad en la apropiación individual de los bienes comunes disponibles conduce necesariamente a la ruina del colectivo (Báez Urbina, 2009).

Argumentaremos en favor de la idea de que tanto la apropiación de BP, la apropiación de recursos comunes (ilustrados acá a través de la categoría de recurso de uso común, RUC), la explotación de la fuerza de trabajo (ausencia de propiedad y apropiación cada vez mayor del producto del trabajo), la precarización (ausencia de seguridad) o la destrucción de derechos sociales y económicos conquistados por los

\footnotetext{
Pensemos en una población de pastores racionales (buscan maximizar su utilidad) que posee un pastizal de uso común y en el que se espera que cada uno mantenga tantas cabezas de ganado como le sea posible. Cada uno intentará aumentar su beneficio personal a espaldas o a costa del grupo, sumando más animales a su rebaño y beneficiándose a tope de los pastos comunales. Ello puesto que, desde el punto de vista de sus intereses, el incremento adicional de un animal más le comportará un beneficio importante, ya que la utilidad conseguida será siempre mayor que el coste a pagar individualmente por la sobreexplotación generada. Pero, desde el punto de vista del universo, el incremento de un animal más por parte de cada particular generará sobrepastoreo, con la consiguiente extinción del recurso.
} 
trabajadores organizados en el siglo XX, tienen que ver con la imposición de dicha modalidad de gestionar la propiedad y la apropiación. Los RUC son bienes de libre acceso (uso no restringido) y de alta rivalidad (el consumo de un agente limita el consumo de otros); esto es, presentan baja exclusión, pero sin oferta conjunta. Se diferencian de los $\mathrm{BP}$ en que, teniendo ambos costes de exclusión altos, los BP son bienes de oferta conjunta y los RUC no. Es decir, mientras la sobreexplotación de un BP no reduce los beneficios potenciales a un tercero, la sobreexplotación de los RUC sí los reduce. ${ }^{4}$ Entre ellos podemos contar "las áreas de pesca, cuencas subterráneas, áreas de pastizales, canales de riego, puentes, estacionamientos, computadores centrales, así como ríos, lagos, océanos y otros cuerpos de agua" (Ostrom, 2000: 66).

De esta manera, sostenemos que el neoliberalismo representa la expresión actual de la apropiación privada de bienes que pertenecen a la comunidad en general, y que en Chile esto es evidente a partir del cambio del patrón de acumulación ocurrido desde 1973. El sistema capitalista es una máquina acumuladora de capital y de poder que se ha venido favoreciendo a costa del bienestar social de las poblaciones desde hace por lo menos tres siglos (Bensaid, 2012; Fontana, 2019; Linebaugh, 2013; Harvey, 2005). Se configuró primero a partir de esquemas basados en la apropiación de la tierra y de los RUC, después con las reglamentaciones colectivas que los trabajadores se dieron entre fines del siglo XIX y el tercer cuarto del siglo XX, para finalmente implantar un diseño institucional expropiatorio de parte importante de los frutos del trabajo humano. Sin duda, una exquisita y excluyente máquina explotadora y expoliadora. Ya en términos más actuales, las dinámicas concentradoras y excluyentes del capitalismo neoliberal, observadas tanto en la división social del trabajo como en la división internacional del trabajo, son hoy síntomas sensibles de lo señalado. La modernidad liberal tardía, entendida como sistema de apropiación ilegitima de los recursos de la sociedad (el producto social como producto del trabajo de todos), impediría la consolidación de un sistema

La depredación de los comunes y la apropiación de ellos se acomete bajo el argumento de que los privados gestan de mejor manera crecimiento económico y de que los privados gestionan mejor la propiedad y los recursos de la sociedad. De acuerdo con esta visión, las camarillas público-estatales son, por definición, ineficientes, burocráticas y en esencia corruptas. También se dice que los BP son bienes de todos y de nadie, por ello, serían mal gestionados. 
de reglas del juego equilibrado y democrático que asegure cierto cúmulo de bienes garantizadores de la existencia social digna. Y nos referimos tanto a los bienes comunes como a los resultados obtenidos por el proceso de trabajo.

Se parte del supuesto de la teoría analítica de la acción colectiva -el individualismo metodológico- que sostiene que los agentes individuales, interactuando de manera interdependiente y cooperativa, generan de manera agregada un producto social a repartir, un BP. La política o los esquemas institucionales favorecen o no los modos de ese reparto que, por definición, es social. Nuestra perspectiva, si bien es analítica, también se construye desde una mirada sociohistórica republicana y democrática (plebeya), que brinda la mirada diacrónica necesaria para abordar de buena manera el fenómeno de la apropiación y la privatización. ${ }^{5}$ Creemos importante mencionar además que dicha mirada, pese a abordar fenómenos de diseño institucional y de apropiación de propiedad social verificados concretamente en el Chile post 1973, parte de reflexiones sociohistóricas y teórico políticas universalistas. De ahí, por ejemplo, muchos de los tipos de la referencia teóricas que se abordan.

En una primera parte se exponen, por un lado, algunas categorías histórico-conceptuales que dan cuenta del proceso de apropiación privada de recursos comunes y que sirven para describir el proceso universal de privatización capitalista del mundo; y, por otro, algunas cuestiones sobre la idea de libertad, propiedad y apropiación desde el enfoque republicano democrático plebeyo. Concretamente, presentamos en primer término el contexto general de los cercamientos y de la apropiación de la propiedad comunal en la Inglaterra preindustrial. Se expone después la Carta Magna, instrumento que muestra el incipiente ánimo de libertad de los barones ingleses del siglo XIII, frente a una tiranía real que se erige sobre un derecho despótico que la hace responsable solo ante Dios; después de ello se expone la Carta de los Bosques, instrumento jurídico que intentará frenar los procesos de privatización de bienes comunes en marcha; seguidamente se hará

Teoría política antitiránica centrada en la idea de la libertad como no dominación y en la universalización de la propiedad. La versión oligárquica no acepta la universalización de esta como medida que garantice la libertad. 
mención a la idea de la acumulación primitiva y de la economía moral antiutilitarista; luego de ello, se aludirá al ejercicio intelectual hecho por Marx sobre el robo de madera, trabajo jurídico y político que dará cuenta del ánimo y de las disputas abiertas por el proceso de privatización de la primera modernidad (posterior al siglo XVI); se termina con la idea de acumulación por desposesión, desarrollada por Harvey a partir del trabajo de Marx, para finalmente cerrar en torno a la relación entre libertad y propiedad en el republicanismo democrático.

En una segunda parte se expone el objeto de estudio propiamente tal del presente texto, esto es, el de la libertad, la propiedad y la apropiación de los comunes en el diseño institucional neoliberal chileno. Acá se entregan algunos conceptos que servirán para desarrollar el análisis de la cuestión de la apropiación de bienes comunes en el diseño institucional chileno contemporáneo. Veremos aspectos, como la cuestión de la propiedad privada en la constitución de 1925 y en la de 1980, el tema de la apropiación privada de BP y de RUC. Finalmente, se concluye con algunas reflexiones sobre la idea de libertad y propiedad en el diseño institucional neoliberal chileno. Su aporte guarda relación con la aplicación de la reflexión inicial, de carácter histórico-conceptual, a la naturaleza y las consecuencias de la implantación del diseño mencionado en el periodo 1973-2020.

\section{Algunos elementos histórico-conceptuales sobre la cuestión de la apropiación de bienes comunes y la propiedad como forma de libertad}

\section{La apropiación y la privatización de los comunes en el capitalismo occidental temprano. Instrumentos y categorías de análisis}

\section{Los cercamientos y la apropiación de propiedad comunal en la antigua Inglaterra}

Uno de los puntos centrales de la historia social europea moderna y uno de los ejes paradigmáticos sobre los que gira la reflexión sobre los comunes y la crítica económico-política, es el tema de los cercamientos de tierra hechos por grupos de poder emergentes en Inglaterra desde el siglo XVI. De hecho, se acepta que los cercamientos, las expropiaciones y la privatización de la tierra por parte de nuevos sectores sociales, 
como la pequeña nobleza gentry, fueron los hitos que marcaron el inicio del patrón de acumulación capitalista. De esta manera, después de que la tierra comenzara a ser mercantilizada durante la Edad Media, y sobre todo con los primeros cercamientos de tierra hechos durante el siglo XVI, la privatización completa de Inglaterra habrá comenzado. Y esto servirá como punto esencial para comprender el permanente proceso de apropiación privada de los recursos de la sociedad, que ha venido significando la formación tanto del Estado como de la modernización capitalista. En palabras de Bensaid: "El movimiento de cercados (de apropiación de las tierras comunales por los grandes terratenientes) comenzó en Inglaterra a fines del siglo XV, pero fue en el siglo XVIII cuando recibió la unción general" (Bensaid, en Marx, 2007: 110), o de Linebaugh:

"Al disolver los monasterios y las tierras comunales correspondientes, Enrique VIII abrió el camino para que una nueva clase, la pequeña nobleza, la gentry, se apropiara de las tierras y se beneficiara de ellas por medio de los cercamientos (...). La disolución de los monasterios, un enorme acto de privatización respaldado por el Estado, que tuvo lugar en 1536, convirtió, mucho más que ninguna otra acción en la larga historia del establecimiento de la propiedad privada en Inglaterra, la tierra inglesa en mercancía" (2013: 67).

\section{La Carta Magna y la Carta de los Bosques ${ }^{6}$}

A continuación, quisiéramos hacer mención a la Carta Magna y a la Carta de los Bosques, dos interesantes instrumentos de diseño institucional que están en la base de la discusión sobre los comunes y la estructura de propiedad en la Europa medioeval. Teniendo en cuenta la definición de comunes que nos plantea Linebaugh, esto es, "bienes gestionados y cuidados según un sistema tradicional que establece ciertas normas en torno a su uso, aprovechamiento y mantenimiento por parte de una comunidad" (2013: 19), ${ }^{7}$ la Carta Magna es un instrumento legal escrito en la Inglaterra del siglo XIII (año 1215), con el que

\footnotetext{
$6 \quad$ Quisiera agradecer al Dr. Andrés Tello por señalarme la existencia de estos valiosos documentos.

7 En la actualidad, la noción de "comunes" puede designar bienes que históricamente se han regido por este sistema tradicional. Incluye tierras, bosques, ríos, pastizales o bienes que, por sus características e importancia para la reproducción y la subsistencia social, pueden gestionarse como tales.
} 
por primera vez se intenta limitar la autoridad del rey frente al poder creciente de la casta de los barones o propietarios agrarios nobles. Es una carta que reúne una serie de principios de diseño institucional que restringen el poder arbitrario del tirano y que garantizan así la libertad de los nuevos actores que irrumpen en el escenario político medieval tardío. La carta consideraba la protección de los derechos eclesiásticos, la protección ante la detención ilegal, el acceso a la justicia inmediata (el llamado habeas corpus) y algunas limitaciones a las tarifas feudales que beneficiaban a la corona. Es considerada hasta hoy como el fundamento de las libertades personales universales y es reconocida como uno de los primeros intentos por instalar el concepto de libertad individual en la cultura jurídico política moderna opuesta al derecho divino monárquico. De esta manera, servirá de inspiración a toda una serie de instrumentos modernos que garantizan las libertades civiles frente a la tiranía de la economía nobiliaria.

En paralelo, la Carta de los Bosques, o Carta Agraria, redactada también en Inglaterra en el mismo periodo, intenta frenar los procesos de apropiación privada de los bienes comunes en la Inglaterra medieval. A partir de la criminalización del derecho consuetudinario de propiedad, definirá los límites de la privatización y regulará la apropiación de bienes comunes por parte de rentistas agrarios y nobles expropiadores. En palabras de Linebaugh: "La criminalización del derecho consuetudinario fue uno de los temas centrales de la historia social inglesa durante el siguiente siglo y medio" (mediados del siglo XVII hasta fines del XVIII, aproximadamente) (Linebaugh, 2009: 107). De esta manera, intentará poner trabas a la imposición universalista del derecho de propiedad moderno que tanto servirá a la instalación del capitalismo y su concepción privada de la estructura de propiedad. Así, en el contexto de cercamientos de tierras en la Inglaterra tardo-medieval, ambos instrumentos representarán dos esfuerzos institucionales precursores y bastante innovadores, tanto desde la perspectiva de las limitaciones al poder centralizado arbitrario, como desde la perspectiva de las limitaciones a la apropiación privada de propiedad común. Juntas, intentarán constituirse como instrumentos de compensación para promover libertades individuales limitando el poder de la corona, y para devolverle el bosque a la gente (Linebaugh, 2013). En definitiva, mientras los principios que regirán la Carta Magna serán los derechos de libertad y propiedad in- 
dividuales, los que regirán la Carta de los Bosques serán los derechos consuetudinarios que aseguran usufructo sobre bienes comunes.

\section{La economía moral de la multitud y la economía política popular}

De manera complementaria, quisiéramos traer a colación los conceptos de "economía moral de la multitud", acuñado por E. P. Thompson, y el de "economía política popular", acuñado por Robespierre, dos conceptos muy cercanos en cuanto a concepción y funcionalidad. El primero de ellos debe ser contextualizado en el contexto de la especulación alcista de los precios de los bienes de subsistencia -fundamentalmente trigo- provocada por propietarios agrarios en el periodo, y el segundo ${ }^{8}$, por allá por 1793 en contra de la economía liberal en consolidación. ${ }^{9}$ Ambos están referidos al conjunto de normas ancestrales, prácticas y valores de uso compartidos por las clases no propietarias en defensa de los bienes comunes de la sociedad. Y esto frente a los ataques cercadores, apropiadores o privatizadores llevados a cabo por los sectores nobles desde fines de la edad media europea. Representaría, entonces, la resistencia de la cultura económica y política popular frente a la oligarquización del diseño institucional (la economía política tiránica de Robespierre) y a la posterior mercantilización de la tierra, el trabajo y el dinero señalada por Polanyi (Domènech, 2012).

La economía moral de los pobres representa entonces la puesta en ejercicio del derecho consuetudinario antiguo que garantiza o blinda la existencia humana: el trabajo, los ingresos o la vivienda; es decir, todos los bienes oponibles en principio a los derechos de propiedad privada. Puesta en operación mediante las tradiciones y los usos y costumbres informales, la economía moral de la multitud o la economía política popular da primacía a la dimensión moral de la economía y no a su dimensión eficientista o instrumental. Está sometida a un cierto derecho natural a la existencia (republicano en un sentido sustantivo) (Bensaid, en Marx, 2007), y parte de la base de que "los derechos políticos

\footnotetext{
$8 \quad$ Fundada "sobre un derecho de propiedad limitado y controlado por las leyes, de tal suerte «que no pueda perjudicar ni la seguridad ni la libertad ni la existencia ni la propiedad de nuestros semejantes», y que se acompaña de derechos sociales concretos" (Gauthier, 2011).

$9 \quad$ Y que además nos recuerda la cuestión del derecho de propiedad y del derecho a la existencia en Marat.
} 
y legales sólo pueden existir sobre una base económica" (Linebaugh, 2013: 27), y de la republicana idea de que "nadie debería enriquecerse hasta que todos se hubieran alimentado" (Linebaugh, 2013: 78).

De acuerdo con Bensaid, el derecho natural, que habría inspirado el texto de la Constitución francesa del Año II (1793), habría subordinado el "derecho de propiedad al derecho de existencia" (Bensaid, en Marx, 2007: 112). "Esta economía política popular es la expresión de un liberalismo político de derecho natural universal, centrado en la libertad, a la cual el derecho a la vida y a los medios de existencia está indisolublemente ligado" (Gauthier, citada por Bensaid en Marx, 2007: 112). Fundada en la idea de que la propiedad es una institución social, ha alimentado buena parte de la versión democrática y progresista del debate político moderno y contemporáneo. Con todo, la idea de la economía moral expresa el derecho a la existencia y en cierto sentido está vigente en la cultura política y económica occidental hasta el siglo XIX.

\section{Karl Marx, el robo de madera y el diseño institucional privatizador moderno ${ }^{10}$}

Como vemos, el cercamiento de tierras, entendido como la apropiación de tierras comunales por parte de grandes terratenientes, comienza en Inglaterra en el siglo XV, y ello trae aparejado una serie de procesos asociados, vinculados todos a la privatización de los recursos de la sociedad. En este contexto, una de las reflexiones más potentes y emblemáticas al respecto es la que hace el joven Marx acerca de la criminalización pública de lo que se denominó "el robo de madera" en la Inglaterra de los siglos XVII y XVIII. Dichas reflexiones, que se encuentran en "Los debates de la dieta renana" (1842), se dan en el contexto de la crítica a la reconversión capitalista del Estado prusiano, y representan los primeros intentos de Marx por pensar la cuestión de los intereses materiales de las masas populares del periodo. Representarán, de esta manera, el tránsito desde su etapa intelectual idealista neohegeliana a la vinculada al estudio de las relaciones económicas y al socialismo científico. En aquellos textos el autor hará un robusto e interesantísimo cuestionamiento de impugnación de la ló-

10 Quisiera agradecer a la doctora (c) Maribel Ramos por mostrarme la existencia de estos valiosos documentos. 
gica del interés privado que se ha venido apoderando tanto del sistema de intercambio económico como de la lógica del diseño institucional capitalista en ciernes. Es en ese sentido, entonces, que el autor de $E l$ Capital se detiene en varios aspectos puntuales sobre el choque frontal entre el derecho consuetudinario, que ampara la lógica de los comunes, y la lógica del derecho de propiedad capitalista moderno en instalación, derecho que fundamenta su avance en la privatización de toda expresión de intercambio libre entre agentes. En efecto, haciendo uso de una inteligente crítica a la definición de propiedad de la madera muerta (la leña, o la madera que ha caído del árbol y que yace a sus pies), es que logra dibujar una de las más interesantes reflexiones sociopolíticas y jurídicas en torno a la idea de los comunes y la estructura de propiedad privada. En tal sentido, Marx aborda, de manera intuitiva y original, las nuevas leyes que penalizan las antiguas prácticas de derecho consuetudinario que han garantizado el derecho a la existencia, como la ley sobre el robo de leña, por ejemplo. En esta dirección, Marx abordará críticamente los procesos de apropiación de tierras y de recursos naturales que se estaban produciendo en Renania y en toda Europa desde el siglo XVII. Así, desarrollando toda una serie de conceptos y lógicas argumentativas novedosas, impugna directamente la lógica que está detrás del ejercicio legislativo privatizador de aquel entonces, y que, salvo pequeñas ventanas históricas democratizadoras universalistas, aún se mantienen en pleno desarrollo hasta el día de hoy. En este sentido, dicha impugnación al acaparamiento privatizador de tierras y recursos comunes constituirá una de las primeras críticas al proceso de instalación de la economía capitalista, cuya lógica implicará, por definición, la acumulación de propiedad y la desposesión de bienes comunes.

Como sabemos, los derechos son prerrogativas, facultades, permisos o licencias, arrebatadas - mediante presión- por los no propietarios organizados frente a los acaparadores de oportunidades de siempre. El patrón de acumulación capitalista se constituye y configura sobre la destrucción de los derechos consuetudinarios de la ciudadanía (derechos que aseguraban un cierto grado de libertad material), y sobre la idea del derecho de propiedad individual moderno que deja sin efecto la idea de la libertad colectiva o material de los miembros de una comunidad. Así, la presión y el monopolio creciente de los ricos de la tierra y las ciudades sobre el diseño institucional, objetará los dere- 
chos consuetudinarios populares tradicionales que a la fecha aseguraban ciertos comunes en Europa occidental, modificando para siempre la estructura de propiedad y la cultura vinculada. Toda la disputa política de los dos siglos siguientes tendrá que ver - en lo medular- con esto, es decir, con la cuestión de la definición de la propiedad de uno mismo, de la propiedad de los recursos materiales e inmateriales relevantes de la sociedad y de la propiedad sobre el resultado del trabajo. En palabras de Bensaid:

"Este período de transición representa, pues, un momento decisivo en la redefinición de las relaciones de propiedad. El derecho pasa a ser entonces un instrumento privilegiado para imponer 'nuevas definiciones de propiedad' en provecho de los propietarios, 'haciendo desaparecer los derechos de uso agrarios no definidos, o acelerando el movimiento de cercamientos' (...) La importancia de lo acontecido en materia forestal da testimonio, pues, por una parte, de la instauración de un nuevo código de definición de la propiedad y, en una perspectiva más amplia, de la imposición de un sistema jurídico basado en un individualismo (condición del intercambio generalizado) en total desacuerdo con los principios consuetudinarios" (Bensaid, 2012: 18).

En definitiva, los artículos de Marx sobre el robo de leña y sobre la situación de los viñadores del Mosela permiten develar las contradicciones que existen en la relación entre sociedad civil y Estado, cuestión que da pie para plantear otro punto asociado, y que se relaciona con lo señalado por Polanyi: la privatización de la riqueza social y la mercantilización de la tierra, del dinero y el trabajo. Ahora bien, dicho proceso de concentración, apropiación y privatización, denominado por Smith "el proceso de acumulación originaria", o llamado por Marx "el llamado proceso de acumulación originaria", se extendería hasta el día de hoy, incluyendo cuestiones biológicas (material biológico humano, animal o vegetal) o intelectuales (propiedad intelectual, apropiación de ideas). En palabras de Bertomeu:

“El fenómeno que Marx denominó acumulación originaria -la destrucción, por parte de la gran empresa capitalista moderna, de la propiedad privada individual, artesanal o campesina, fundada en el propio trabajo personal- ha cobrado en las últimas décadas un impulso extraordinario, en forma de desposesión neocolonial 
de las economías naturales y tradicionales del tercer mundo. Implica hoy, entre otras cosas, la mercantilización y privatización de la tierra y consecuentemente la expulsión de las poblaciones campesinas, la conversión de distintos tipos de derechos de propiedad comunales, colectivos y estatales- en derechos exclusivos de propiedad privada gran capitalista, la privación del acceso a los bienes comunales y la supresión de formas alternativas consuetudinarias de producción y consumo" (2005).

\section{La acumulación por desposesión de David Harvey}

Finalmente, quisiéramos mencionar el concepto de acumulación por desposesión propuesto por Harvey (2003 y 2007) y desarrollado a partir de la idea de acumulación primitiva u originaria de Marx. En efecto, estos procesos de privatización, desnacionalización, mercantilización y financiarización acaecidos desde mediados de los 70, funcionarían como línea de continuidad con procesos similares a los descritos por Marx para la naciente economía industrial capitalista bajo su categoría de "acumulación primitiva". En palabras de Harvey, la acumulación por desposesión puede entenderse como el conjunto

"amplio de procesos, que incluyen la mercantilización y privatización de la tierra y la expulsión por la fuerza de las poblaciones campesinas; la conversión de varios tipos de derechos de propiedad (comunal, colectiva, estatal, etc.) en derecho de propiedad privada exclusivos; la supresión del acceso a bienes comunales; la mercantilización de la fuerza de trabajo y la supresión de formas alternativas (indígenas) de producción y consumo; los procesos coloniales, neocoloniales e imperiales de apropiación de bienes (incluidos los recursos naturales); la monitorización del intercambio y los impuestos, en particular sobre la tierra; la trata de esclavos; y la usura, la deuda nacional y más recientemente el sistema de crédito. El Estado, con su monopolio de violencia y su definición de la legalidad, desempeña un papel decisivo en el respaldo y promoción de estos procesos" (Harvey, 2003: 116).

Ahora bien, y ya para ir centrándonos en nuestro objeto de análisis, quisiéramos señalar que entenderemos a la acumulación por desposesión como el amplio, complejo y profundo conjunto de procesos de privatización, desmantelamiento de derechos universales, desnacio- 
nalización, precarización y trasferencia de riqueza de abajo hacia arriba en la estructura social, vividos por el conjunto de las clases media y baja entre mediados de los años 70, y que continuaría hasta el día de hoy. De esta manera, suscribimos la hipótesis de Harvey $(2003,2007)$, que señala que prácticamente todas las características del proceso de la acumulación primitiva señaladas por Marx siguen patentemente presentes en todos los procesos de privatización y desinstalación de las regulaciones institucionales universalistas, desarrollistas y nacional populares que en otros textos hemos denominado como descolectivización (Domènech, 2013; Báez Urbina, 2017). De esta manera, la "mercantilización y privatización de la tierra y la expulsión forzosa de las poblaciones campesinas, la conversión de diversas formas de derechos de propiedad - común, estatal, colectiva, etc. - en derechos de propiedad exclusivos; la supresión del derecho a los bienes comunes" (Harvey, 2005: 113), o los propios procesos neocoloniales de apropiación de recursos naturales han venido a conformar el paisaje de esquilma sobre los recursos y los derechos de la población en todas las latitudes hasta el día de hoy. De hecho, la "supresión de derechos comunes conquistados a lo largo de años de tenaces luchas (tales como la protección social, la salud pública o las jubilaciones) y su retorno al dominio privado ha constituido una de las formas políticas más agresivas de desposesión llevadas a cabo en nombre de la ortodoxia neoliberal" (Bensaid, en Marx, 2007: 122).

\section{Libertad republicana y democracia incondicional. ¿Por qué lo material importa?}

El liberalismo sostiene que la forma en que se organiza la política y la economía de una comunidad, el llamado "diseño institucional", debe ser compatible con las preferencias (deseos y creencias sobre oportunidades) de los agentes, y con los modelos de virtud personal que los agentes evalúen como adecuados para sí mismos (Gargarella, 1999). En este sentido, las reglas del juego deben ser compatibles con las preferencias y las intuiciones morales de las personas y deben dar la sensación de que no restringen las preferencias individuales de estas; esto es, deben fomentar la idea de libertad individual. Defiende la autonomía individual, el individualismo y el atomismo sociales, distinguiendo claramente entre lo público y lo privado, o entre la esfera personal y la de la política (Gargarella, 1999). Para la teoría liberal, los agentes 
preexisten a cualquier arreglo institucional y poseen un estatuto de jerarquía mayor que cualquier esquema de coordinación institucional que se utilice para maximizar beneficios. De esta manera, el Estado y el orden político no deben interferir en la moral privada; y el Estado, por un lado, deberá asumir una posición neutral frente a las preferencias de los sujetos, y, por otro, solo servirá para ciertas tareas mínimas de la vida en común como la defensa de la estructura de propiedad privada en sus diferentes escalas (diferencias entre particulares y entre naciones). En ese sentido, blindará los derechos individuales de lo que denominan la "tiranía de la mayoría". Existiría, entonces, un conjunto de derechos individuales inviolables (y que tendrían origen prácticamente divino) que deben blindarse de la voluntad y de la soberanía popular por medio de instituciones contramayoritarias: se es libre en la medida en que no hay interferencia externa a la condición individual por parte de las mayorías. Relacionado a ello, el derecho individual a la propiedad privada es un tipo de derecho que emana de la naturaleza y la propia condición humana; esto es, un derecho que formaría parte de una ley cuasinatural. En estos términos, se supone que, dado que el ser humano es ontológica, deontológica y cronológicamente precedente a la sociedad política (Estado), los derechos y deberes emanarían de una dignidad que es intrínseca a la naturaleza de la persona humana; y, por tanto, serían anteriores al Estado y superiores a este. La libertad liberal como no interferencia arbitraria y el principio de propiedad privada individual serán, entonces, los centros nodales del discurso liberal estándar que tomaremos como referencia a discutir (la libertad negativa en Berlin).

A diferencia de aquello, la tradición republicana democrática ${ }^{11}$ sienta sus fundamentos en su idea de libertad como ausencia de dominación, dominación que exige el goce de independencia material y de la universalización de la propiedad. De ahí que se pueda hablar del carácter propietarista del republicanismo; esto es, sólo puede ser

11 Entre sus autores más relevantes podemos contar a Ephialtes, Pericles, Aspacia de Mileto, Protágoras o Demócrito, entre los clásicos griegos de versión democrática y plebeya, o a Aristóteles o Cicerón entre los clásicos griegos de versión no democrática y oligárquica. Por su parte, en términos modernos, podemos contar con los trabajos de Marsiglio de Padua, Maquiavelo, cierto Locke, cierto Smith, Rousseau, Jefferson, Paine, Kant, Robespierre y el propio Marx. En términos contemporáneos podemos contar con los trabajos de Pettit y Skinner, por ejemplo. 
libre quien es propietario de sí, y también propietario de una cantidad de bienes que aseguren su propia libertad. De esta manera, será libre quien dispone de un conjunto de bienes materiales que lo doten de niveles relevantes de autonomía e independencia material frente al resto, o quien goce de un conjunto de bienes que hagan que no tenga que pedir permiso a un otro para vivir dignamente (Marx en su Crítica del Programa de Gotha). En palabras de Domènech, "la forma republicana de gobierno exige como condición necesaria una distribución más o menos igualitaria y no polarizada de los medios de producción y subsistencia. Libre es, en la noción republicana clásica, quien puede vivir por sus propios medios, quien no necesita pedir permiso a otro particular para poder vivir" (2010).

Como vemos, la cuestión de la libertad material es importante para la tradición republicana y alude fundamentalmente a la cuestión de la dimensión propietarista y de la autonomía de los agentes (propiedad restrictiva para la vertiente oligárquica ${ }^{12}$, o propiedad universal para la vertiente democrático-plebeya). Es en ese sentido concreto, entonces, que la tradición republicana plebeya haya planteado a través de su historia soluciones institucionales contrarias a la concentración, a la centralización y al monopolio de la propiedad y la concentración de las oportunidades, al rentismo oligárquico, a la instauración y consolidación de enormes barreras a la entrada para la producción de mercados no concentrados, etc. ¿Qué instituciones ha propuesto? Los "cuatro acres y una mula", los procesos de reforma agraria, la idea de la función social de la propiedad sintetizada en el Artículo 27 de la Constitución mexicana nacida de la revolución de Zapata y Villa ${ }^{13}$, o la renta básica universal de ciudadanía que vendría del discurso compensatorio de Paine. En palabras de Hudson:

\footnotetext{
12 Respecto de esto, "la tradición oligárquica del republicanismo ha sostenido que todos se refiere a los ricos, a los propietarios, a los que son libres porque su independencia material les confiere la capacidad de obrar como libres (...) la versión oligárquica del republicanismo diseña la concentración del poder en manos de los ciudadanos propietarios, mientras que la corriente demo-republicana diseña la constitución política del todos" (Guanche, 2018).

13 El cual señala expresamente: "La propiedad de las tierras y aguas comprendidas dentro de los límites del territorio nacional, corresponde originariamente a la Nación, la cual ha tenido y tiene el derecho de transmitir el dominio de ellas a los particulares, constituyendo la propiedad privada".
} 
"Es lo que buscaron los escolásticos de la civilización europea del siglo XIII a través de la Ilustración y del florecimiento de la economía política clásica: una economía libre de ingresos por rentas, libre de intereses creados empleando privilegios especiales para la extracción de renta. En manos de los neoliberales, al contrario, un mercado libre es libre para que una clase rentista favorecida por los impuestos pueda extraer interés, renta económica y precios de monopolio" (2011).

Todas ellas medidas institucionales de corte igualitarista, que intentan universalizar la propiedad y democratizar las oportunidades económicas del conjunto de la población; cuestión que hoy es absolutamente necesaria, debido a los niveles nunca vistos de concentración y centralización económica que han venido desmontando los esquemas institucionales democráticos centrados en una esfera pública construida sobre intereses civiles comunes. A decir de Domènech, una "economía tiránica alimentada por grandes poderes privados substraídos al orden civil común de los libres e iguales, enfeudados en nuevos privilegios plutocráticos" (2017). Pues bien, la propiedad importa para la consecución de la ansiada libertad y esto es un tema no solo de importancia económica, sino también, política. En palabras de Robespierre: "La primera ley social es aquella que garantiza a todos los miembros de la sociedad los medios para existir" (2 de diciembre de 1792 en la Convención) (Bosc et al., 2005: 154).

No cooperación y apropiación de BP y RUC en el diseño institucional neoliberal chileno

Esta segunda parte del texto la dedicaremos, por un lado, a aplicar las lógicas históricas y conceptuales descritas al modelo neoliberal chileno; por otro, a intentar demostrar cómo el diseño institucional neoliberal chileno ha venido girando en torno a la idea de que la elite en los 80 dejó de cooperar con el financiamiento de la sociedad (provisión de $\mathrm{BP})$, y de que, desde aquella década, ha venido apropiándose de buena parte de los BP y los RUC disponibles en el país. El neoliberalismo será entendido, entonces, como una máquina excluyente y apropiadora que representa el esfuerzo contemporáneo gran capitalista de explotación y expoliación sobre el trabajo y los derechos adquiridos históricamente por la población trabajadora. Habría sido impuesto 
por las elites rentistas globales como proyecto restituyente del poder de clase (Harvey, 2007) y, particularmente en Chile, como reacción al proceso de transición al socialismo propuesto por el programa de la Unidad Popular (Báez Urbina, 2017; Gárate Chateau, 2012). En ese sentido, y usando libremente los términos de la metáfora que Keynes usa para describir el período 1930-1973, la "eutanasia del rentista", el neoliberalismo (1973-2008, o incluso hasta la actualidad) no sería más que su venganza, "la venganza del rentista". Dos citas interesantes que nos pueden servir para abrir el acápite y fundamentar la idea de que en nuestra actualidad es el tiempo de la privatización global y creciente del mundo, de la privatización de empresas del Estado, de los servicios dirigidos a la población, de la educación, de la información, etc. Como señala Bensaid:

"A la hora de la globalización mercantil y la privatización generalizada del mundo, los artículos de Marx sobre el robo de madera revisten una inquietante actualidad. La compra de la fuerza de trabajo ajena establece una relación de apropiación/expropiación, no sólo de esta fuerza de trabajo, sino también de los servicios públicos, del ahorro popular, del consumo, de los cuerpos puestos en espectáculo, del espacio abandonado a la especulación hipotecaria e inmobiliaria. La privatización afecta no sólo a empresas públicas, sino también a la educación, la información, el derecho (por la generalización del contrato privado en detrimento de la ley común), la moneda, los saberes, la violencia, en resumen, el espacio público en su conjunto" (2012: 43).

"Más allá de la apropiación de las materias primas, de los recursos energéticos y de la mano de obra barata, incluye la apropiación, a través del turismo, de la historia cultural bajo una mirada mercantil o incluso a través del saqueo de patrimonios culturales (...) Esta nueva ofensiva de la acumulación neoliberal pasa por la destrucción de derechos sociales y por la criminalización de las resistencias populares y de los movimientos sociales" (Bensaid, en Marx, 2007: 122-123).

Como vemos, podríamos señalar sin problemas que existiría una línea de continuidad histórica entre los cercamientos de la acumulación originaria o primitiva, planteada por Smith y Marx en los siglos XVIII y XIX sobre los recursos comunes de la naciente modernidad inglesa, y 
los nuevos cercamientos o cercamientos contemporáneos, esto es, de bienes estatales, sociales, biológicos, intelectuales, etc. Si antes la justificación de dichos cercamientos era mediante el argumento del crecimiento de la productividad agraria que terminaría con las hambrunas de los comienzos de la modernidad, los argumentos actuales tendrían que ver con la capacidad de innovación. No obstante, y como bien señala Bensaid, mientras los cercamientos de bienes intelectuales, por ejemplo, tendrán que ver con la idea de $\mathrm{BP}$, los cercamientos de tierras tienen que ver con el concepto de RUC.

\section{La cuestión de la propiedad privada en las constituciones de} 1925 y de 1980

En la perspectiva de contribuir a demostrar la evolución histórica de los procesos de apropiación de BP y RUC por parte de la elite y la involución de los derechos de las mayorías, abordaremos sucintamente la cuestión de la libertad individual y la propiedad a partir de dos o tres citas puntuales de los apartados dogmáticos de las constituciones de 1925 y de 1980. Respecto del texto de 1925, Grez señala que los principios que la Asamblea Constituyente de Obreros e Intelectuales del mismo año acuerda como guías para la Constitución de 1925, fueron:

"la socialización de la tierra y de los medios de producción; la forma federal del gobierno; el deber del Estado de coordinar y fomentar la producción y asegurar la distribución de los productos; el sistema colegiado de gobierno tanto a nivel comunal, nacional como de los Estados federados; la organización del Poder Legislativo en base a "cámaras funcionales", compuestas por representantes (...) de los gremios organizados; la separación de la Iglesia del Estado; la enseñanza gratuita desde la escuela hasta la Universidad, colocando su dirección en manos de los maestros, padres y estudiantes; la igualdad de derechos políticos y civiles de ambos sexos y la supresión del ejército permanente" (2009: 12).

Es decir, todo un conjunto de principios de carácter republicanodemocrático, que garantizaban medianamente la existencia social y que aparecían ante la intuición ético-política más básica como bastante diferentes de los principios prácticamente libertaristas (o liberalcatólicos) y privatistas que subyacen a la de 1980. Respecto de este último texto, sabemos sobre la visión de mundo que materializa. Sabemos 
que exalta ideales como la libertad negativa (Cfr. Isaiah Berlin), plasmándola en torno a un conjunto de ideas y valores como la propiedad privada, los derechos individuales, la libertad de enseñanza, la libertad de asociación y de empresa (Cristi, 2008). También sabemos que, en su versión original, el texto que lo antecede y que le da fundamento es el de las "Bases de la Institucionalidad". De hecho, en su capítulo dedicado a los derechos, deberes y garantías fundamentales, encontramos una proclamación bien acotada que exalta valores como la dignidad de la persona y los derechos que fluyen de la persona humana, esto es, la familia como núcleo fundamental de la sociedad, la subsidiaridad y la servicialidad y la legitimación del Estado para contribuir al bien común, la limitación de la soberanía por el respeto al ser humano, la supremacía de la Carta Fundamental, el Estado de Derecho y la proscripción al terrorismo (Cea Egaña, en Báez Urbina, 2017).

De esta manera, los principios que inspiran el texto de 1980 ya los encontramos en la Declaración de Principios del Gobierno de Chile, publicados por la junta militar en 1974 (Báez Urbina, 2017). Entre ellos, podemos contar los derechos naturales, la servicialidad del Estado, el bien común como objetivo final del nuevo diseño institucional, el respeto al principio de subsidiaridad, cuestión que en última instancia supone la aceptación del derecho de propiedad privada y de la libre iniciativa económica, y por tanto de la descentralización funcional o separación entre poder político y poder social (Báez Urbina, 2017). Respecto de la cuestión de las definiciones básicas, por ejemplo, mientras el Artículo 2 de la Constitución de 1925 señala, por ejemplo, que: "La soberanía reside en esencialmente en la Nación, la cual delega su ejercicio en las autoridades que esta constitución establece" (no contempla limitaciones al ejercicio de la soberanía), el Artículo 5, Inciso $2^{\circ}$, de la Constitución de 1980 señala que: "El ejercicio de la soberanía reconoce como limitación el respeto de los derechos esenciales que emanan de la naturaleza humana" (Báez Urbina, 2017). Gran diferencia. Ahora bien, y respecto del derecho de propiedad, por ejemplo, la Constitución del 25, en su Artículo 10, N 10, Inciso $3^{\circ}$, señalaba: “Cuando el interés de la comunidad nacional lo exija, la ley podrá⿴ reservar al Estado el dominio exclusivo de recursos naturales, bienes de producción u otros que declare de importancia preeminente para la vida económica social o cultural del país. Propenderá⿴囗 asimismo a la conveniente distribución de la propiedad y a la constitución de la propie- 
dad familiar". En cambio, el Artículo 19, Numeral 21, Inciso $2^{\circ}$ del texto del 80, señala claramente que: "El Estado y sus organismos podrán desarrollar actividades empresariales o participar en ellas sólo si una ley de quórum calificado los autoriza. En tal caso, esas actividades estarán sometidas a la legislación común aplicable a los particulares, sin perjuicio de las excepciones que por motivos particulares justificados establezca la ley, la que deberá ser, asimismo de quórum calificado".

Se destaca claramente que la actividad empresarial del Estado debe ir ligada al principio de subsidiaridad; asimismo, se crea el recurso de amparo económico, cuestión destinada a denunciar las infracciones vinculadas. De esta manera, si el texto constitucional del 25 estaba construido sobre la idea de la protección y la seguridad social y colectiva de los derechos de los trabajadores por medio del Estado social o proto social, la del 80 lo está sobre la idea de la no interferencia de cualquier organización sobre la estructura de preferencias y oportunidades de orden utilitarista de un agente abstracto X.

\section{La no cooperación en la provisión de BP y la cuestión de la estructura impositiva regresiva}

Para analizar la cuestión de la estructura impositiva, definamos primero la cuestión de la no cooperación. No cooperar significa elegir la alternativa que te beneficiará individualmente al no tener que contribuir con los costes de la provisión de un bien que beneficiará al universo de agentes: un BP. Como sabemos, una de las innovaciones más importantes y ventajosas para las elites financieras y comerciales desde los años 80, a nivel global (aparte de la de generar crédito barato a clases populares y medias para solventar la necesidad de consumo de los productos industriales en momentos de baja de los salarios reales), es la rebaja de impuestos a las grandes rentas. Respecto de esto, Harvey señala, por ejemplo, que, en el periodo de Reagan, la rebaja de impuestos en EE. UU. al tipo impositivo máximo para las personas bajó del 70 al 28\% (2007). Desde aquel momento, el del cambio de paradigma de la cultura de los derechos al de los deberes, las elites ya se rehúsan a financiar la sociedad. En Chile, por ejemplo, a diferencia de los países desarrollados, no funciona un sistema impositivo integrado, en el que empresas pagan impuestos y esa plata va directamente al tesoro público, sino que funciona uno desintegrado en el cual las empresas (no sus dueños), si bien pagan impuestos, luego sus dueños recuperan 
el capital en su planilla de impuestos personales. "Adicionalmente, en 1984 se crea el FUT (Fondo de Utilidades Tributarias), que permite que los impuestos se paguen sobre las utilidades efectivamente retiradas y no sobre la base de su existencia. Ello ha permitido que los dueños de las grandes empresas (principalmente) se hayan beneficiado del uso de esos recursos a través de sociedades de inversión que operan como vehículos financieros, con el fin de crear una zona franca donde no se pagan impuestos" (Fundación Sol, S/F). De esta manera, se puede afirmar que en Chile hoy rige un sistema tributario pro elite, en el que quienes más ganan pagan menos por el financiamiento de los BP en términos proporcionales. Es decir, en el país existe un esquema tributario destinado a la acumulación de rentas por parte de las elites financiero-comerciales y rentistas. Y lo que no pagan, lo acumulan en cuentas de paraísos fiscales. Así, se autoeximen de contribuir a la producción de los BP que la sociedad necesita y exige para su funcionamiento normal y corriente.

\section{Ejemplos sobre la apropiación privada de BP: Las}

privatizaciones de las empresas públicas, de la seguridad socialy de los bienes intelectuales

La privatización de empresas públicas. Una de las cuestiones más relevantes del llamado quiebre institucional en Chile (dictadura cívico-militar) es el de la apropiación privada de empresas del Estado. En efecto, mientras la derecha económica argumentaba contra la eficiencia del Estado, se apropiaban sin oposición política o social de un enorme conjunto de empresas públicas en funcionamiento. Fue una especie de botín de guerra que quedó en manos de nuestros modernizadores y sus asociados. En efecto, en Chile, mientras la derecha política privatizaba, la derecha económica compraba a precios irrisorios. Una comisión parlamentaria determinó que entre 1973 y 1990 fueron 725 las empresas estatales que fueron vendidas a precios bajísimos a grupos económicos durante la dictadura. Y ahí nadie se acordó de "la institucionalidad" o de respetar "la propiedad". Incluso arriesgando una hipótesis de corte político culturalista, el economista Gabriel Palma señala que "parte de la tragedia actual (de este país) es que la impunidad de la ratería de algunos Chicago Boys \& Asociados quedó en la médula del modelo". Y añade: “Todos esos crímenes quedaron impunes". Para mayores antecedentes sobre el proceso de apropiación, consultar el 
elemental texto de María Olivia Mönckeberg, Premio Nacional de Periodismo, denominado "El saqueo de los grupos económicos al Estado chileno" del año 2001 en donde se menciona, por ejemplo, que entre 1985 y 1990 se privatizó, entre otras, la Empresa Nacional de Electricidad (ENDESA), la Compañía de Acero del Pacífico (CAP), la Industria Azucarera Nacional (IANSA), la Línea Aérea Nacional (LAN Chile), la Empresa Nacional de Telecomunicaciones (ENTEL), Laboratorios Chile o a la Sociedad Química y Minera de Chile (SOQUIMICH), la que incluso quedó en manos de un exyerno de Pinochet.

La privatización del sistema de seguridad social y las Asociaciones de Fondos de Pensiones (AFP). Lo primero que debemos señalar es que un sistema de pensiones democrático, universal y ciudadano, junto al sistema público de salud y el de educación, representan tres de los principales pilares institucionales que aseguran y garantizan la existencia social digna, representan los pilares básicos de reproducción de la vida humana. Concordamos con Richard Sennett en que la implementación de los sistemas de jubilación y de salud con financiamiento público, tan propios del siglo $\mathrm{XX}$, pueden entenderse sin problemas como una forma instituida de redistribución de la riqueza social, porque, bajo el principio de la cooperación intergeneracional, transfiere beneficios de las generaciones más jóvenes a las generaciones mayores. Dicho esto, debemos recordar que, en el país, la dictadura militar, al modificar el diseño institucional que regiría por completo el sistema de coordinación de intereses en la sociedad chilena desde los 80 en adelante, incluyó la privatización del sistema de pensiones. En efecto, el año 1981 se reemplaza el sistema integrado de reparto universal por uno de capitalización individual privado; se reemplaza un sistema de pensiones basado en el concepto de seguridad social por uno de ahorro forzoso, basado en el de rentabilidad individual y centrado en la idea de riesgo financiero, cuestión que merece ser analizada por lo menos desde dos dimensiones: desde el punto de las bajas pensiones que esto genera y desde la inyección de capital fresco que las contribuciones individuales agregadas suministran al sistema financiero nacional mes a mes. En efecto, el tema no es solo el de las bajas pensiones que, evidentemente, también es un tema de importancia crucial para la seguridad socioeconómica y psicológica de la población civil, sino que también es el del enorme volumen de capital fresco que mes a mes es usado por 
la elite para enriquecerse a costa de los contribuyentes, cuestión que, desde el punto de vista de este escrito, es muy importante. ${ }^{14}$

El tema es que en estos 40 años las AFP han acumulado tanto poder económico y político (a diferencia de la desacumulación de poder sufrida por parte de la ciudadanía, lo que recuerda un juego de suma cero) que es evidente que no renunciarán nunca a los privilegios adquiridos. En todo caso, tienen razón cuando señalan casi todos los días por los medios que legalmente la plata es de los contribuyentes individuales y privados del sistema. Lo dicen en TV sobre todo, en momentos en que algún actor político osa discutir y criticar los fundamentos doctrinarios del sistema. Y lo hacen para que la ciudadanía no se sienta defraudada o expropiada. Pero claro, pese a ello, ésta no puede retirar los fondos. Otra ficción liberal. Como sabemos, Chile no tiene un sistema de pensiones, sino un mecanismo de ahorro individual forzoso que tiene como objetivo inyectar capital al mercado financiero. A decir de Kremerman (2015):

"Se crean en 1981 las AFP, a través de las cuales, utilizando las cotizaciones de los trabajadores para sus pensiones futuras, se capitaliza a los grupos económicos, invirtiendo en acciones y bonos para que estos puedan crecer y reproducirse (...) capital fresco, casi a costo cero, proporcionado por todos los chilenos que cotizan (...) Luego estos mismos grupos financian a la política para que se mantengan las reglas del juego".

Como vemos, es absolutamente necesario avanzar en Chile en la creación de un esquema institucional que garantice el derecho básico de tener una pensión justa, y ahí la discusión sobre la renta básica universal que plantea el republicanismo democrático nos lleva a la cuestión de fondo: el derecho a la existencia digna del conjunto de la población.

La apropiación de BP en el ámbito intelectual. En este pequeño acápite nos queremos servir, como recurso general de análisis, del concepto de "general intellect" propuesto por Marx en los Grundrisse de 1858, es decir, la idea de que existe una inteligencia social, una

$14 \quad$ Para hacernos una idea, con los US\$170 mil millones que tienen los fondos de las AFP a la fecha, se podrían comprar dos empresas multinacionales del tamaño de Microsoft y Facebook. 
inteligencia acumulada colectiva, creada tanto por conocimientos y saberes, como por técnicas productivas acumuladas generación tras generación, y que en definitiva es de carácter público. De acuerdo con lo que hemos descrito, es un BP. Por otro lado, representa un saber colectivo acumulado, una forma general de la inteligencia humana que tiende a convertirse en fuerza productiva. El punto es que dicha inteligencia colectiva, entendida como BP, se privatiza, es decir, es apropiada privadamente por parte de la sociedad (la elite financiero comercial) para dirigir el proceso productivo y obtener ventajas y ganancias de capital realmente voluminosas. En efecto, para los fines de este escrito, lo interesante de la cuestión, aparte de que el concepto sirve de base para poner de manifiesto la idea de que la sociedad existe y que, más que un conjunto agregado de resultados de esfuerzos individuales (en cierta medida representa un tercer excluido emergente que sirve de base - da soporte - al logro individual: se triunfa individualmente sobre las espaldas de los demás) ${ }^{15}$, representa un BP apropiable y que claramente es apropiado privadamente por las elites de turno (hoy, la más antidemocrática de todas, la financiero comercial).

De esta manera, hoy en nuestro entorno claramente podemos observar cómo avanza y se consolida la privatización de bienes intelectuales o de resultados de investigación financiada con fondos públicos, por ejemplo. La idea de la patentabilidad y la propiedad intelectual avanzan frenéticamente y el cercamiento de los descubrimientos de la ciencia son el pan de cada día. Y esto no tiene que ver con cuestiones genéricas o distantes para las masas, como la apropiación privada de ideas académicas, científicas (así, en abstracto), sino con la apropia-

15 Normalmente olvidamos, como señala Elster, que la ganancia individual de cada quien depende de las ganancias de todos. Todos tienen que jugar para que cada quien gane individualmente. Esto es, la ganancia individual se "descuelga", se configura a partir del funcionamiento del juego en general, se produce a partir de la apropiación individual del resultado del juego en general. Por otro lado, aparte de que inventaron la ficción doctrinaria de los derechos naturales a la propiedad individual, cobran mucho por el trabajo de decidir y dirigir el proceso de producción social. Finalmente, también olvidamos que los ricos no son sujetos especiales, como el sentido común político conservador sugiere; no es un tipo de vanguardia dotada de atributos especiales, notables y ahistóricos. No son independientes de las relaciones sociales en las cuales habitan y en las que se constituyen. Son ricos o propietarios precisamente por ellas. Como los demás, son empujados por el resto, como si estuvieran instalados sobre las espaldas de los demás. Las clases poderosas son el resultado de la instalación y la consolidación de un orden basado en el despojo y la expropiación naturalizada por los relatos oligárquicos fantasiosos sobre dones naturales y religiosos y la cultura del emprendimiento individual. 
ción de resultados de investigación vinculados a la estructura genética del cuerpo humano y de la vida. En palabras de Bensaid, "socialización del trabajo intelectual y la apropiación privada de ideas" (Bensaid, en Marx, 2007: 121). En cuanto al trabajo académico, por ejemplo, "que se financia con dineros del Estado, es entregado gratuitamente a las editoriales que luego cobran a los Estados para que otros investigadores puedan acceder a esos estudios. En la práctica y tal como está organizada la difusión de la investigación científica (...) «se le entrega la soberanía del conocimiento académico mundial a un puñado de empresas transnacionales con afán de lucro»" (Berger et al., 2018). Acá es importante señalar además cómo los emprendimientos privados gran capitalistas se vienen apropiando de los resultados de investigación financiados con dinero de los contribuyentes. En efecto, es sabido que Apple, por ejemplo, para producir en masa sus aparatos IPhone en el sureste asiático, utiliza tecnología obtenida con investigación de frontera desarrollada con proyectos de la NASA financiados con dinero de los contribuyentes; y se enriquece privadamente de manera permanente con ello. Respecto de esto, los ejemplos sin innumerables.

Ejemplos sobre la apropiación privada de RUC: el agua, las cuotas de pesca, las tierras del pueblo mapuche y la privatización de la propiedad fiscal territorial

La apropiación del agua. El actual Código de Aguas fue promulgado durante la dictadura cívico-militar a través del DFL $\mathrm{N}^{\circ} 1.122$ de octubre de 1981. Este instrumento legal instauró, de forma inédita a nivel mundial, un mercado del recurso hídrico cimentado sobre la idea de la propiedad privada del agua y de que el beneficiario de derecho de aprovechamiento pudiera comercializar directamente con éste, independientemente de que el titular fuera dueño de tierra o no. Por otro lado, este mecanismo le arrebató al Estado su rol de garante del uso racional y del derecho social al agua, reemplazándolo por criterios económicos de carácter privado (Fundación Sol, S/F). Esto sirve de telón de fondo para comprender el proceso de apropiación del recurso. Hoy, en momentos de que Chile está siendo afectado por problemas serios de sequía (e incluso desertificación de las zonas centro norte y central), particulares beneficiados por derechos de aprovechamiento privados, cedidos durante la dictadura y por los gobiernos de la Concertación de Partidos por la Democracia, quienes legitimaron la privatización del 
agua, además de beneficiarse legalmente de un recurso antes considerado como derecho social, roban agua para regar campos de frutos destinados a la exportación. Y esta situación pasa particularmente en la Provincia de Petorca, V Región Cordillera, la zona símbolo de la sequía y el robo del recurso antes público. De esta manera, la legislación vigente beneficia a la producción privada de recursos agrícolas, a la vez que perjudica a amplias masas de consumidores y campesinos empobrecidos, que no disponen del recurso ni siquiera para el consumo humano. Apropiación legal e ilegal de RUC.

Las cuotas de pesca. Algo parecido ocurre con las cuotas de pesca. Hace unos pocos años se dio la discusión política sobre la renovación de contratos para la captura de peces en el borde costero y en alta mar. La discusión enfrentó a distintos tipos de actores privados, entre otros a quienes querían optar a permisos de extracción de por vida (el gran capital pesquero, quienes ya tenían permisos que vencían en el periodo de discusión de la ley), el gobierno y los pescadores artesanales que, además de plantear la necesidad de montar esquemas de explotación de recursos más racionales, de todas maneras, proponían reglas del juego asociadas a sus necesidades económicas locales. Finalmente, y como era de esperar, la ley benefició a los industriales, pero, como es sabido, y tras la divulgación de los escándalos políticos de proporciones que desentrañaron la existencia de redes de corrupción que traficaban influencias entre el gran empresariado pesquero y los partidos de centro derecha, derecha y extrema derecha (captura del Estado por parte del gran capital rentista), la ley fue dejada sin efecto. Actualmente la nueva discusión se encontraría en proceso. Esto creemos que nos sirve para dejar planteado otro asunto asociado. El del escaso interés de invertir en investigación e innovación (I+D) que tendría una elite rentista altamente beneficiada con la apropiación de recursos naturales (RUC).

Las tierras del pueblo mapuche. A través del incentivo para la forestación de grandes extensiones de terreno en el sur del país, y con el objetivo de potenciar el sector económico forestal mediante la plantación de especies forestales específicas, en 1974 fue promulgado el $\mathrm{DL} \mathrm{N}^{\circ} 701$. El periodo original de incentivo o bonificación fue otorgado por 30 años, aunque luego fue renovado primero por 15 años más con efecto retroactivo (1998), y luego por dos años más. Dicho 
instrumento ha venido beneficiando en los últimos 40 años al gran empresariado forestal (CMPC, Arauco y MASISA), en un esquema de extracción altamente concentrado, monopolista y dependiente de los recursos del Estado. De más está decir que este esquema extractivo y rentista ha venido teniendo un fuerte impacto en la destrucción del bosque nativo y su reemplazo por especies exóticas útiles a la industria. Pese a que aún no se realizan estudios detallados acerca del impacto de dicho esquema extractivo (y creemos que nunca serán hechos), se está discutiendo extender los permisos e incentivos a la industria. No obstante ello, y respecto del impacto social directo en la región, organizaciones de pueblos mapuches, por ejemplo, "han manifestado que no han sido consultadas, de acuerdo al Convenio 169 de la OIT y el derecho internacional, señalando que no ha existido consulta previa, ni restitución de sitios sagrados, ni la consideración de un nuevo enfoque indígena" (Fundación Sol, S/F). Dentro de ello, dicha situación ha venido generando conflictos armados entre fuerzas de seguridad del Estado y grupos mapuches organizados en defensa de las tierras ancestrales. Aún no existe evaluación alguna respecto a los impactos económicos, sociales y ambientales. Apropiación privada de RUC con financiamiento del Estado, es decir, de la comunidad general.

La privatización de la propiedad fiscal territorial. Otro de los puntos importantes del problema de la apropiación - aunque menos observable - es el de la privatización que en los últimos años se ha venido haciendo del territorio. En este sentido, compartimos una frase que demuestra el sentido final y definitivo del fundamento del diseño institucional neoliberal chileno: para el Estado neoliberal chileno, "el territorio siempre estará mejor administrado en manos de personas que del Estado" (El Desconcierto, 2018). Dicha frase, vertida por el propio titular del Ministerio de Bienes Nacionales de este gobierno, demuestra el espíritu del tratamiento neoliberal hacia la propiedad pública y la propiedad social, o la función social de la propiedad antes descrita. Pues bien, queremos cerrar esta parte con una noticia de 2018, que demuestra ya no solo el espíritu sino la puesta en operación de dicha doctrina. Según hemos recabado, el 51\% del territorio chileno es de propiedad fiscal, es decir, es de propiedad de todos, del cual un buen porcentaje será concesionado a privados en el marco de un nuevo plan de licitaciones operado por este gobierno. Una nueva forma que en- 
cuentra el gobierno neoliberal de turno (2018-2022) para privatizar lo que aún queda de país. Apropiación de RUC. En este sentido, bajo el entendido de que, desde la presidencia, se ha instruido al titular de la cartera de Bienes Nacionales de hacer un buen uso de los recursos territoriales del país - y eso en la doctrina neoliberal significa necesariamente privatizar-, el ministro de Bienes Nacionales señala el 2018:

"El Presidente (...) nos encomendó hacer buen uso del territorio. Y a través de este plan de licitaciones hacemos justamente eso: poner a disposición el territorio para que, mediante proyectos que muevan a las regiones y finalmente, al país, hagamos buen uso de los bienes que nos pertenecen a todos (...) Se trata de la $12^{\mathrm{a}}$ versión de este tipo de plan de licitaciones que realiza el ministerio en su historia, y busca promover la inversión en seis sectores productivos de acuerdo con las vocaciones de uso que presenta cada terreno".

A modo de conclusión: libertad y apropiación en el diseño institucional neoliberal chileno

Desde el punto de vista descriptivo, y como hemos venido tratando de argumentar, creemos que el neoliberalismo representa la expresión contemporánea de la apropiación privada de los recursos de todos o provistos por todos. En este sentido, creemos que el diseño institucional gran capitalista en su versión contemporánea, lo que el periodismo político ha venido insistiendo en llamar "neoliberalismo", representa la imposición forzada y generalizada del uso privado de propiedad común, y ha venido avanzando silenciosamente en su tarea apropiatoria a partir de la no cooperación con la provisión de BP (baja de impuestos y fuga de beneficios hacia paraísos fiscales), la apropiación de BP (empresas públicas, pensiones o bienes intelectuales, p. e.) y de RUC (agua, cuotas de pesca, tierras del pueblo mapuche, privatización de propiedad territorial, p. e.). Y si a esto se suma la explotación sin freno de la fuerza de trabajo (ausencia de propiedad, apropiación cada vez mayor de producto del trabajo, estancamiento de salarios reales a partir de los 70), la precarización completa de la vida (ausencia de seguridad laboral), o la destrucción de derechos sociales y económicos conquistados por los trabajadores en el siglo $\mathrm{XX}$ a través de ingentes luchas sociales (salud, educación, pensiones), tenemos un panorama económico y psicosocial desolador para las amplias mayorías. De he- 
cho, de los cinco problemas sistémicos del capitalismo planteados por Wolfgang Streeck, esto es, estancamiento, redistribución oligárquica, saqueo del dominio público, corrupción y anarquía global, la apropiación y la privatización asoman como dos de las cuestiones naturalmente asociadas a dichos problemas.

Por otro lado, las disputas políticas en el campo distributivo de los últimos años se han venido dando entre procesos de nacionalización (vistos como actos democratizadores desde abajo y como robo ilegítimo - expropiación - desde arriba) y procesos de privatización forzados y ejecutados autoritariamente. Mientras la concentración de la propiedad alcanza niveles nunca antes vistos en la historia humana y la clase alta avanza mucho más velozmente que el resto de la sociedad, se instala y consolida un Estado (subsidiario y tecnocrático, no un Estado social) cada vez más racionalizado y autoritario, para cuidar y dar soporte político a la sobreacumulación de las elites financieras y comerciales generada en estas últimas décadas. En una época que pretende hacer que todo sea una mercancía, y en la que se ha instalado y masificado la cultura de la competencia generalizada (todos contra todos: una forma de lucha del más fuerte por recursos escasos útiles para todos), por lo menos en el contexto de la transición a la democracia en Chile se ha instalado un mercado político formal - con bastantes barreras a la entrada - sobre un diseño institucional liberal autoritario.

Rompieron el contrato unilateralmente y reclamaron hegemonía para liderar en solitario la producción social de un nuevo ciclo. Ganaron la lucha de clases del siglo XX e impusieron un régimen de acumulación radical que recuerda la economía liberal anterior a la crisis de 1930 (la Belle Époque). Prometieron inclusión social, pero por medio del mercado, no del Estado; no obstante, dicha inclusión tuvo un costo de un tamaño tal vez mayor que los beneficios generales reportados. La economía privada no regulada generó enormes utilidades a una pequeña porción de la población e incorporó a algunos pequeños sectores al progreso y a los beneficios de la globalización; sin embargo, la mayoría quedó permanentemente en situación de precariedad y vulnerabilidad frente a un estado de cosas que premió el mérito por sobre los derechos. La gran masa de trabajadores fue incluida, pero mercantilmente, no socio-estatalmente, lo que implicó que los beneficios fueron apropiados individualmente y no colectivamente 
por medio de instituciones asociadas a la organización de la sociedad (el Estado social: la acción colectiva organizada socialmente). Y esto está vinculado con un tema para nosotros central: que el costo de los logros vinculados a la inclusión, la accesibilidad y la superación de la pobreza no son otra cosa que la gran desigualdad generada como efecto no esperado. Es decir, como los beneficios son apropiados individualmente y como dichos beneficios no redundan en la provisión de BP, poco a poco se va minando aún más el sentido colectivo de lo producido por todos. Visto desde el punto de vista individual, cada uno se beneficia marginalmente del producto social generado en estos últimos 40 años (y con un endeudamiento privado nunca visto), pero desde el punto de vista del colectivo (haciendo una economía política de la situación y apelando a la contradicción permanente entre intereses individuales y colectivos), con dicha estrategia el capital se ha beneficiado estratosféricamente mucho más que los supuestos beneficiados de dicha estrategia. Y con esto queremos decir que el costo final de la estrategia de superación de pobreza implementada no sería otro que el del evidente aumento de la desigualdad social agregada. Así, el costo de la integración social mercantil es el aumento de la concentración de poder económico, político y cultural. Ahora bien, como actualmente la macroscopía no tiene buena prensa, este tipo de análisis es desechado y silenciado.

Se ha venido protegiendo un espacio de libertad para unos pocos, se ha venido creando un espacio institucional que protege a los sectores sociales favorecidos por el libre mercado global. Promoviendo la idea de libertad liberal, se ha venido protegiendo la propia libertad para apropiarse de todo y para asegurar la explotación y la usurpación del resultado del trabajo de todos. Lo que se ha venido haciendo es construir un espacio de seguridad política, económica y cultural que garantice la posición dominante de unos pocos.

El siglo XIX liberal/conservador nos ha concedido el derecho a la libertad respecto de la tiranía (el triunfo definitivo de la Carta Magna inglesa), tenemos la ciudadanía política liberal, pero nos falta la económica, la republicana, la democrática. En ese sentido, las preguntas son las mismas de siempre: recordando la cláusula de Locke (al apropiarme de algo debo dejar tanto y tan bueno a los demás), ¿cómo pueden volverse bienes privados los bienes naturales que han sido producidos por la 
propia naturaleza? ¿Con qué derecho algunos agentes privados se han venido apropiando privadamente de los bienes que la naturaleza nos brindó a todos gratuitamente? Pues bien, con el diseño institucional neoliberal se ha despojado a las poblaciones de todo cuanto pertenece a la ciudadanía (resultado del trabajo personal), apropiándose además de los BP y de los RUC. Desde hace 30 años que debemos pagar por salud, por educación, por seguridad, por información, por agua; es decir, básicamente por todos los bienes relevantes de la sociedad. Y esto, el espíritu apropiador de la máquina neoliberal contemporánea -que hoy se ve como algo absolutamente evidente y problemático-, fue regulado por la Carta de los Bosques en la Inglaterra del siglo XIII, fue previsto por Marx en su análisis sobre el robo de madera en la Renania de los siglos XVII y XVIII, e intentado frenar por una idea económica que puso el acento hasta el siglo XIX en las cuestiones morales del intercambio entre particulares.

Ahora bien, respecto del argumento normativo, se necesita de diseños institucionales que garanticen una vida digna para las grandes mayorías, y acá el rol del Estado y de una ciudadanía organizada es crucial. Como señala De Francisco, "el Estado es expresión de la correlación de fuerzas sociales que, a su vez, depende del régimen de propiedad y de la estructura de su distribución". Si los sindicatos y los movimientos sociales son débiles, si no están suficientemente organizados, no tienen poder de negociación para hacer frente al apetito voraz de los propietarios y rentistas de turno. Si no están suficientemente organizados y dispuestos a dar la pelea en el terreno de la disputa por sus derechos, la ley y el diseño institucional se inclinará siempre inequitativa e invariablemente en favor de los intereses de los rentistas y del capital. Como señala Žižek: "Debemos volver a confiar en el Estado. No me canso de repetirlo: el neoliberalismo no existe. Sólo es una ideología que casi nunca se lleva a la práctica. En los últimos años, el Estado ha estado interviniendo constantemente en favor de las elites económicas. Lo que hay que intentar ahora es que trabaje para todos. En la crisis del 2008 salieron mejor parados los países donde el estado era más fuerte" (Lenore, S/F). En este sentido, precisamos de enfoques que vuelvan a poner encima de la jerarquía valorativa pública "la economía moral por sobre la competencia de todos contra todos, de la solidaridad sobre el cálculo egoísta, del derecho consuetudinario de los 
pobres sobre el privilegio de los poseedores, del interés público sobre la codicia privada" (Bensaid, 2012: 56).

\section{Referencias bibliográficas}

a) Artículos y capítulos de libros

Báez Urbina, F. (2017). "Diseño institucional y des colectivización en Chile: Del Estado social al Estado neoliberal", en Revista Izquierdas, $\mathrm{N}^{\circ} 34$, pp. 50-79.

Domènech, A. (2013). "Socialismo: ¿de dónde vino? ¿qué quiso? ¿qué logró? ¿qué puede seguir queriendo y logrando?", en M. Bunge y C. Gambetta (Editores), ¿Tiene porvenir el socialismo? Buenos Aires: EUDEBA, pp. 71-124.

Hardin, G. (1968). "The tragedy of the commons", en Science, vol. 162, $\mathrm{N}^{\circ} 3859$, pp. 1243-1248.

Grez, S. (2009). "La ausencia de un poder constituyente democrático en la historia de Chile", en Revista Izquierdas, Año 3, N5, pp. $1-21$.

Rancière, J. (2017). El reparto de lo sensible. Estética y política. Santiago de Chile: LOM.

Ostrom, E. (2000). El gobierno de los bienes comunes: La evolución de las instituciones colectivas. México, DF: UNAM, CRIM, FCE.

b) Libros

Bensaid, D. (2012). Los desposeídos. Karl Marx, los ladrones de madera $y$ los derechos de los pobres. Buenos Aires: Prometeo.

Bosc, Y., F. Gauthier y S. Wahnich (Editores) (2005). Robespierre, Maximilien. Por la felicidad y la libertad. Discursos. Madrid: El Viejo Topo.

Fontana, J. (2019). Capitalismo y democracia 1756-1848. Cómo empezó el engaño. Barcelona: Crítica.

Gárate Chateau, M. (2012). La Revolución Capitalista de Chile (19732003). Santiago de Chile: Ediciones Universidad Alberto Hurtado.

Gargarella, R. (1999). Las teorías de la justicia después de Rawls. Barcelona: Paidós.

Harvey, D. (2003). El nuevo imperialismo. Madrid: Akal.

Harvey, D. (2007). Breve historia del neoliberalismo. Madrid: Akal. 
Marx, K. (2007). Los debates de la dieta renana. Buenos Aires: Gedisa.

\section{c) Otros}

Berger, J. J., M. L. Rodríguez y A. Rescaglio (2018). “iQué hacer para cambiar las reglas que someten la investigación científica al mercado del conocimiento?", en CIPER Chile,

https://ciperchile.cl/2018/12/03/que-hacer-para-cambiar-las-reglasque-someten-la-investigacion-cientifica-al-mercado-delconocimiento/, revisado el 24-II-2019.

Bertomeu, M. J. (2005). “Republicanismo y propiedad”, en Sin Permiso, http://www.sinpermiso.info/textos/republicanismo-y-propiedad, revisado el 12-03-2020.

Desconcierto, El (2018). "El territorio siempre estará mejor administrado en manos de personas que del Estado: La frase del ministro Ward que Bienes Nacionales prefirió borrar de Twitter", en El Desconcierto,

http://www.eldesconcierto.cl/2018/12/04/el-territoriosiempre-estara-mejor-administrado-en-manos-de-personas-que-del-estado-la-frase-del-ministro-ward-quebienes-nacionales-prefirio-borrar-de-twitter/, revisado el 3-VIII-2019.

Domènech, A. (2010). "Economía política y tradición histórica republicana: El caso de Adam Smith”, en Sin Permiso, http://old. sinpermiso.info/articulos/ficheros/smithrepublicano.pdf, revisado el 21-VII-2019.

Domènech, A. (2012). “50 años después: Prólogo a la nueva edición castellana de La formación de la clase obrera en Inglaterra de E. P. Thompson", en Sin Permiso,

http://www.sinpermiso.info/textos/50-aos-despus-prlogoa-la-nueva-edicin-castellana-de-la-formacin-de-la-claseobrera-en-inglaterra-de, revisado el 8-V-2019.

Domènech, A. (2017). "El socialismo y la herencia de la democracia republicana fraternal", en El Viejo Topo,

https://www.elviejotopo.com/topoexpress/el-socialismo-yla-herencia-de-la-democracia-republicana-fraternal/, revisado el 2-VII-2019

Fundación Sol (s/f). "Los 11 pilares dictatoriales que sostienen el actual modelo", en Fundación Sol, http://www.fundacionsol. 
cl/wp-content/uploads/2013/09/LOS-11-DEL-11-MEDIOS. pdf, revisado el 12-VIII-2019.

Harvey, D. (2005). "El nuevo imperialismo. Acumulación por desposesión", en CLACSO, http://biblioteca.clacso.edu.ar/clacso/ se/20130702120830/harvey.pdf, revisado el 2-XI-2019.

Gauthier, F. (2011). "Robespierre ha sido un gran dirigente de la democracia en acción", en Sin Permiso,

http://www.sinpermiso.info/textos/robespierre-ha-sidoun-gran-dirigente-de-la-democracia-en-accin-entrevista, revisado el 10-IX-2019.

Guanche, J. C. (2018). “Prólogo socialismo con gorro frigio", en Sin Permiso,

http://www.sinpermiso.info/textos/quienes-somos-todosprologo-a-la-democracia-republicana-fraternal-y-el-socialismo-con-gorro-frigio, revisado el 2-XII-2019.

Hudson, M. (2011). "La oligarquía financiera contra la democracia social europea", en Sin Permiso,

http://www.sinpermiso.info/textos/la-oligarqua-financiera-contra-la-democracia-social-europea, revisado el 7-VI2019.

Kremerman, M. (2015). "La dictadura del Capital: el legado vigente de Pinochet", en El Mostrador,

https://www.elmostrador.cl/noticias/opinion/2015/09/11/ la-dictadura-del-capital-el-legado-vigente-de-pinochet/, revisado el 1-V-2019.

Linebaugh, P. (2009). "Elinor Ostrom: un Premio Nobel al legado republicano-democrático de Tom Paine”, en Sin Permiso,

http://www.sinpermiso.info/textos/elinor-ostrom-un-premio-nobel-al-legado-republicano-democrtico-de-tom-paine, revisado el 8-VII-2019.

Linebaugh, P. (2013). "El manifiesto de la Carta Magna. Comunes y libertades para el pueblo", en Traficantes de Sueños,

https://www.traficantes.net/sites/default/files/pdfs/El\%20 Manifiesto\%20de\%20la\%20Carta\%20Magna-TdS.pdf, revisado el 10-IV-2019.

Lilti, A. (2018). "Cuando se ahorcaba a los pobres", en Sin Permiso, http://www.sinpermiso.info/textos/cuando-se-ahorcaba-alos-pobres, revisado el 5-VI-2019. 
Ministerio de Bienes Nacionales (2018). "Bienes Nacionales pone a disposición 179 terrenos para proyectos productivos en todo Chile", en Ministerio de Bienes Nacionales, http://www.bienesnacionales.cl/?p=33861, revisado el 3-VII-2019.

d) Tesis

Báez Urbina, F. (2009). El problema de la acción colectiva y los movimientos de oposición ciudadana a la provisión de bienes de uso colectivo: El trazado del AVE a su paso por Barcelona, un caso relevante de estudio. Tesis para optar al grado de Doctor en Sociología. Barcelona: Universidad Autónoma de Barcelona. 